\title{
O NeORREALISMO SEGUNDO O JOVEM EduARDo Lourenço
}

\section{Neorealism according to the young Eduardo Lourenço}

\author{
Luís Bueno*
}

\section{RESUMO}

No prólogo de seu livro Sentido e forma da poesia neo-realista, Eduardo Lourenço faz a seguinte afirmação: "O 'neo-realismo' como significativa realidade literária nasceu após a sua teorização, como vestimenta de uma Ideologia cuja força histórica, sugestão e potencial universalidade, a exigiam". Pertencente à geração que construíra aquele amplo debate teórico, mas mais jovem do que seus principais representantes, Lourenço entra na discussão noutra situação, quando já há um conjunto expressivo de obras a serem discutidas. Neste trabalho tratamos dos primeiros artigos críticos de Eduardo Lourenço, publicados na revista Vértice de Coimbra, em que analisa romances de Carlos de Oliveira e Fernando Namora, assinalando sua importância, mas já estabelecendo uma discussão franca sobre os limites do movimento que, àquela altura, iniciava seu percurso rumo a uma posição de hegemonia nas letras portuguesas.

Palavras-chave: Eduardo Lourenço, neorrealismo, crítica portuguesa. 


\begin{abstract}
Eduardo Loureço affirms, in the foreword of his book Sentido e forma da poesia neo-realista [Meaning and form in neorealist poetry]: "Neorealism as a relevant literary reality was born only after the development of its theory, like a garment for an Ideology demanded by its historical power, prospects, and potential universality". As an intellectual that belonged to the generation that built the theory, but younger than his main companions, Lourenço started his critical career in another moment, when the theory had already been developed and many literary works had been published. In this paper, we take into account Lourenço's first critical essays, published at Vértice review, whose subjects are Carlos de Oliveira's and Fernando Namora's novels. There he underlines the importance of neorealism and, at the same time, establishes a deeply honest discussion about the fragilities of the literary movement in a time when it was starting to ascend to an hegemonic position in Portuguese Literature.
\end{abstract}

Keywords: Eduardo Lourenço, neorealism, Portuguese criticism.

As primeiras publicações de Eduardo Lourenço não estão no campo da crítica literária, mas sim no da criação. ${ }^{1}$ Trata-se de um conto, "Ti curandeiro", publicado em janeiro de 1943 na seção "Um conto por dia" do Diário Popular de Lisboa, e de um poema, "Aceitação", saído no terceiro número da revista Vértice de Coimbra, em 1944:

Fez-se manhã e noite

o meu amor por ti

que o teu

nunca amanheceu.

Melhor assim.

Se amanhecera

1 A produção de Eduardo Lourenço encontra-se listada no site da Universidade de Évora. Disponível em: < http://www.eduardolourenco.uevora.pt/index.php?option=com_content\& view $=$ article $\& i d=58 \&$ Itemid $=78 \&$ lang $=$ en $>$. Acesso em 30 nov. 2013. 


\author{
morrera \\ que tudo morre em mim \\ ente o sim e o não \\ da minha contradição. ${ }^{2}$
}

Em uma entrevista de 2009, ele explicaria essa sua experiência como poeta:

As pessoas pensam que lá por Portugal ser um país de poetas é óbvio que, na adolescência, toda a gente escreveu poesia. E tenho um poema, por volta dos meus 18 anos, que dei a conhecer... [...] A explicação para isso é que pertenço a uma geração de jovens escritores e poetas - o Carlos de Oliveira, o João José Cochofel - e sem falar, à época que andei por Coimbra, de um mito cultural da cidade chamado Torga. ${ }^{3}$

Como não é dessa mais que bissexta carreira de poeta que trataremos aqui, a explicação de Eduardo Lourenço nos interessa porque ele inclui o seu nome entre destaques do neorrealismo. Embora seja evidente que essa seja a sua geração, sua trajetória como crítico não o filia propriamente ao movimento. Mas é ligado a ele que sua estreia como crítico se deu, em fevereiro de 1945, na mesma revista Vértice, com um artigo sobre o romance Itha doida, de Joaquim Ferrer, no qual localizaria exatamente "uma mistura de queirosianismo e de realismo concreto, cru e chão dos nossos neo-realistas". ${ }^{4}$

Esse número tem particular importância na história de uma revista literária que foi um fenômeno raro, e não só em Portugal: sairia ininterruptamente por mais de quatro décadas e teria ainda uma segunda série, agora ligada a uma grande editora, a Caminho, que durou até 2010. Lançada em 1942, e dirigida por Carmo Vaz, Raul Gomes e Francisco Melo, a revista teve três números, um por ano. Esses primeiros números são por assim dizer ecléticos e não chegaram a dar-lhe uma identidade neorrealista - ou qualquer outra. Isso mudaria no número em que Lourenço se iniciaria como crítico. Carlos de Oliveira e João José Cochofel, exatamente os poetas neorrealistas

2 LOURENÇO, Eduardo. Aceitação. Vértice, Coimbra, n. 3, fev. 1941. p.9. Citaremos todos os textos a partir de sua publicação original nos periódicos. A partir de outubro de 2014, eles estão disponíveis também em livro, já que a Fundação Calouste Gulbekian publicou-os no segundo volume das Obras completas, organizado por António Pedro Pedra, ao qual ainda não tivemos acesso.

3 LOURENÇO, Eduardo. "Meus heterónimos são máscaras transparentes”. Ler. Livros \& Leitores, Lisboa, n. 84, out. 2009. p. 55. Entrevista a Carlos Câmara Leite.

4 LOURENÇO, Eduardo. Ilha doida de Joaquim Ferrer. Vértice, Coimbra, n.4-7, fev. 1945. p. 61. 
mencionados por Lourenço na entrevista - assumiriam sua direção ao lado de Raul Gomes, o único remanescente do grupo inicial. ${ }^{5}$

O começo da década de 40 é um momento decisivo para a história do neorrealismo. O movimento surgira de forma dispersa em $1933 \mathrm{com}$ a publicação esparsa de pequenos periódicos, muitos deles ligados a escolas secundaristas, que foram se avolumando aos poucos. A partir de 1936 ganha uma outra dimensão com o espaço que passa a ocupar em $O$ Diabo. Este jornal cultural lisboeta fora fundado em 1934. Passa a ser dirigido por Rodrigues Lapa no final de dezembro de 1935, que o abre de vez para os jovens intelectuais de esquerda que estariam entre os principais nomes do neorrealismo, como Álvaro Salema, João Pedro de Andrade e Mário Dionísio. Em 1937, funda-se no Porto uma revista, Sol Nascente, que também se tornaria importante plataforma do movimento. Isso sem contar as dezenas de páginas literárias de jornais por todo o país que seriam tomadas de assalto pelos "novos".

Em 1940, a ditadura simplesmente fecha, de um só golpe, O Diabo e Sol Nascente. As publicações menores também acabam. Outras revistas, fundadas em 1939, como Sintese e Altitude - esta última dirigida, entre outros, por Cochofel - tiveram vida curta. É assim que Vértice, a partir do número em que Eduardo Lourenço nela começa a publicar crítica, iria se tornar o grande veículo do neorrealismo.

E nos seus primeiros textos Eduardo Lourenço fala, se não como um neorrealista, pelo menos em defesa do neorrealismo. É claro que não se trata de defesa cega e apaixonada, mas sim de um ponto de vista que, mais do que justificar o movimento, recusa-se a aceitar o rebaixamento de sua produção, em que os inimigos do movimento insistiam, e procura distinguir, no individualismo de cada autor e cada obra, o que haveria de válido e de falho na experiência neorrealista.

Em parte pelo menos isso se dá porque o crítico começa sua trajetória em posição bastante diversa daquela em que começaram os intelectuais de sua geração, mas um pouco mais velhos, que deram início ao movimento. O próprio Lourenço, em seu livro de 1968, Sentido e forma da poesia neo-realista, indica o que marcou esses intelectuais:

O "neo-realismo" como significativa realidade literária nasceu após a sua teorização, como vestimenta de uma Ideologia cuja força histórica, sugestão e potencial universalidade, a exigiam. Pode dizer-se que toda a dialéctica e o drama interno do neo-realismo -realismo português. Coimbra: Angelus Novus, 2008. 
português decorrerá desta singular relação entre teoria ideológica e prática literária, entre a antecipação constituída por um horizonte ideológico, funcionando à maneira do Ideal regulador kantiano, embora em contradição consigo mesmo, e a necessidade e a vontade de lhe oferecer o corpo correspondente. Não se pode dizer que tenha sido este o processo normal da irrupção das vagas literárias mais características da literatura nacional. ${ }^{6}$

De fato, Gaibéus de Alves Redol, aquela que seria conhecida como a obra inaugural do neorrealismo, só apareceria no final de 1939, quando o movimento já havia se firmado como força ativa da literatura portuguesa por meio do debate político, teórico e crítico que levou a cabo, como dissemos, desde 1933. Não é coincidência que, quando essa teorização está no auge e a polêmica com o grupo da revista Presença já assume grandes proporções, a atenção se volte para a literatura social brasileira e todos os principais críticos do movimento passem a escrever sobre os novos autores brasileiros afinados com o posicionamento de esquerda do grupo, como se estivessem ansiosos por tratar de literatura na prática. Também não é coincidência que, a partir de 1940, com o surgimento de romances e livros de poemas neorrealistas, o acompanhamento pelos jornais e revistas portuguesas da nova literatura brasileira vá diminuir sensivelmente até se tornar residual. ${ }^{7}$

Quando Eduardo Lourenço estreia na crítica, embora apenas cinco anos tenham se passado desde a publicação de Gaibéus, a produção neorrealista já era considerável. Toda a coleção de poesia Novo cancioneiro fora editada e os principais romancistas já haviam estreado: além do próprio Redol, Fernando Namora, Carlos de Oliveira, Manuel da Fonseca e Soeiro Pereira Gomes. Ou seja, o jovem crítico já tem um corpus a partir do qual se posicionar, ao mesmo tempo em que não precisa participar das polêmicas, que sempre obrigam a tomadas de posição pouco flexíveis, para dizer o mínimo. Diferentemente do que acontecera com Mário Dionísio ou Joaquim Namorado, por exemplo, sua crítica pôde exercer-se, desde o princípio, no exame das obras, e não na consideração de princípios que norteariam o que ainda estava por vir. Além disso, já havia uma crítica contrária às obras neorrealistas, e não a seus princípios, o que permitiria um debate mais concreto sobre forma literária.

6 LOURENÇO, Eduardo. Sentido e forma da poesia neo-realista. 2 ed. Lisboa: Gradiva, 2007. p. 12 .

$7 \quad$ Procurei mostrar esse movimento em: BUENO, Luís. O Brasil invade Portugal - Literaturas brasileira e portuguesa na década de 1930. In: PONCIONI, Claudia; ESTEVES, Manuel da Costa. Hommes de lettres et la Res publica au Portugal e au Brésil. Paris: Michel Houdiard, 2013. p. 225-236. 
Tudo isso fica muito claro no artigo publicado em maio de 1945 por ocasião do lançamento da segunda edição do segundo romance de Carlos de Oliveira, Alcateia. Veja-se esta observação logo no início do artigo:

Influenciados pelo Jorge Amado da fase neo-romântica e julgando-se obrigados, por uma compreensão inadequada da luta entre dois mundos diferentes, os primeiros neo-realistas não evitaram o falseamento de alguns personagens. Isto que a crítica notou e exagerou, desaparece, ou quase, em Casa na duna. ${ }^{8}$

Da mesma maneira que admite um problema na produção dos primeiros neorrealistas, o falseamento de alguns personagens, não deixa de registrar que a crítica teria exagerado esse defeito. Com isso se coloca em posição de defesa do movimento, sem deixar de admitir que seus críticos possam ter alguma razão. Essa afirmação segue uma outra, que a antecipa e a contextualiza: "Duma vez para sempre, o centro concreto do nosso romance foi desviado do regionalismo, do folclorismo e do exotismo, de muitas páginas de Aquilino, Ferreira de Castro e mesmo Alves Redol, para a condição humana, simples, directa e concreta de nossos camponeses e proprietários rurais". 9

Carlos de Oliveira aparece, aqui, como autor capaz de superar um problema que, afinal, não era apenas do neorrealismo, mas do romance português como um todo, perceptível em autores anteriores ao movimento, com Aquilino Ribeiro e Ferreira de Castro, ainda que o aponte também em Redol. Segundo Lourenço, já em seu romance de estreia Carlos de Oliveira fora capaz de tratar da condição humana de personagens de classes sociais opostas.

Nos anos que antecederam a produção propriamente literária neorrealista, a discussão se centrava em algo mais teórico - portanto abstrato: a função da literatura. Por aí se estabeleceu a oposição com o grupo de Presença. Ambos os grupos concordavam que a literatura existe para tratar do "humano", para compreendê-lo e alargá-lo. Acontece que, para os neorrealistas, o humano é algo material, as condições sociais em que diferentes homens vivem. Para os presencistas, o humano comporta algo transcendente, que o define. Simplificando um debate complicado e exprimindo-o em termos de mera oposição, não estamos muito longe da polarização que marca a tradição crítica brasileira entre os "regionalistas" e os intimistas". 
Neste texto sobre Alcateia, o que Eduardo Lourenço faz é implodir qualquer possibilidade de oposição assim tão simples e, dessa maneira, chegar à grande questão para a avaliação do neorrealismo no momento em que escreve: a limitação que o engajamento teria imposto à produção do movimento até ali. Ele a enfrentará a partir da análise da constituição das personagens:

Sob esse ponto de vista, Carlos de Oliveira afasta toda a acusação de esquematismo ideológico que é costume dirigir ao neo-realismo. Nem Cosme Sapo, nem o dr. Carmo, aparecem a uma luz desfavorável pelo facto de serem o primeiro degrau da escala social do mundo que rejeita João Santeiro e Leandro. O dr. Carmo é honesto de seu ponto de vista e outro qualquer faria o mesmo. Monologando, justifica-se a si próprio e o autor toma parte nesse drama, mostrando como a desilusão vai alastrando na sua vida, mesmo na hora do triunfo. ${ }^{10}$

Mais uma vez vemos a postura de Lourenço de, ao enfatizar a qualidade do trabalho de Carlos de Oliveira, defender o neorrealismo como um todo. Ele vai direto ao ponto e nega haver esquematismo na constituição das personagens de Alcateia, algo que insinua ver em Jorge Amado, cuja influência sobre os jovens romancistas portugueses fora apontada. Para sustentar essa sua leitura, evoca um personagem, o dr. Carmo. Por um lado, afirma que esse homem rico não é propriamente mau por ser rico, como o esquematismo ideológico de esquerda tenderia a fazer. E isso seria possível em virtude da qualidade de tratamento dado por Carlos de Oliveira a dois distintos aspectos. O primeiro é o desenho em si do personagem, cujas motivações se encontram em elementos de enredo, internos portanto às ações e não numa pressuposição ideológica que tenderia a fazer de todos os proprietários um mesmo personagem. O segundo é de técnica literária mais miúda, o uso do monólogo interior que também contribui para expor as motivações individuais de seus atos, como a difícil relação que tem com o filho.

Mas isso não significa que Lourenço irá alçar Carlos de Oliveira à condição de autor perfeito. Ao contrário, ele apontará uma limitação imprevista em sua literatura:

Se há em Carlos de Oliveira um parti-pris de esquematismo, não é de ordem ideológica, mas estética e psicológica. A secura bem vincada de seu estilo, a sua violência sombria reflectem-se no caráter de seus personagens. O humor é possivelmente a ausência 
mais visível no tecido psicológico dos seus romances. Raríssimos os personagens que riem alguma vez. ${ }^{11}$

Numa inversão espetacular, o eventual defeito dos romances de Carlos de Oliveira é atribuído àquilo que, em geral, segundo seus detratores, não preocuparia os neorrealistas, a psicologia dos personagens. Para Lourenço eles são figuras monoliticamente tristes que, quando riem, "são sempre mordazes, cáusticos". ${ }^{12}$ Mas daí volta àquilo que interessaria primordialmente aos neorrealistas, que é a expressão do real. Afinal, para Lourenço, na gente portuguesa do campo "há o riso aberto, há mesmo uma capacidade de sorrir por cima da miséria da vida, que torna seu destino ainda mais espantoso" ${ }^{13}$. Ou seja, a caracterização cerrada de psicologias individuais fortes, marcadas pela tragédia da vida, vazada em estilo seco, faria com que Carlos de Oliveira, de certa forma, fosse menos realista ao caricaturar o homem rural português por retirar dele um outro traço que $o$ consistiria e, assim, o simplificaria.

A análise é bastante complicada, conseguindo desviar-se do lugar-comum da crítica neorrealista sem no entanto cair no lugar-comum que a ela se opunha.

É também em função da psicologia dos personagens que Eduardo Lourenço, meses depois, em fevereiro de 1946, tratará do terceiro romance de Fernando Namora, $A$ casa da malta, "uma novela que merece ser destacada pelos defeitos e qualidades que possui", ${ }^{14}$ segundo o crítico. A grande qualidade do livro seria a condução do enredo, a junção dos diferentes planos da narrativa. O grande defeito, exatamente o contrário do que ocorria com Carlos de Oliveira: a pobreza da psicologia dos personagens:

De resto é defeito de todo o nosso neo-realismo. Na generalidade, os seus cultores mostram-se incapazes de transcender o "típico" para alcançar o "individual-típico". As situações de muitos personagens são "típicas", mas dum típico que já é comum: a rapariga traída pelas condições em que vive, o trabalhador explorado etc. ${ }^{15}$

Lido isoladamente, este trecho parece ir na direção oposta àquela em que ia o texto anterior, assumindo de vez uma falência geral do movimen-

1 Idem, ibidem.

12 Idem. Ibidem.

13 Idem, ibidem.

14 LOURENÇO, Eduardo. Casa da malta de Fernando Namora. Vértice, Coimbra, n. 22-26, fev. 1946. p. 28.

15 Idem, p. 29 
to, mais do que indicar o problema de um autor ou de um livro. O restante do texto apagará essa impressão. Em sua conclusão, Lourenço apontará capítulos em que Namora supera esse defeito e arremata:

Se o poder de sugerir é fundamental na criação literária, quem é capaz de o conseguir algumas vezes, consegui-lo-á sempre, como decerto sucederá ao autor desta novela, quando se resolver a conceber as situações e a recriar os seus tipos duma forma pelo menos tão audaciosa como a que demonstra no seu processo de contar. ${ }^{16}$

É com o olho num futuro promissor e mais maduro que o texto se encerra, e isso sinaliza um desdobramento positivo não só para a obra de Namora, mas também para todo o neorrealismo.

Todavia, não é neste final que a relativização do atribuído defeito neorrealista se desenvolve, mas na abertura do artigo, no primeiro dos dois pequenos capítulos em que se divide. É no segundo que temos as considerações referidas sobre Casa da malta. No primeiro, o que se vê é uma breve mas decisiva discussão sobre arte engajada que surpreende num crítico de 22 anos que mal se iniciara na carreira. E aqui aquela sóbria posição de defesa do neorrealismo se manifesta.

Ele começa declarando a simples validade da experiência do movimento: "Se a nossa crítica não tivesse de ser feita como ainda é, dentro duma ilha burguesa, já não havia motivo para insistir no que há de novo e valioso na literatura neo-realista. Além de ser um facto universal é um ponto de vista efectivado em obras irrecusavelmente belas". ${ }^{17}$

A seguir, virá sua mais decisiva defesa :

Como toda arte e na medida em que o acto humano de criar se pode considerar livre, a arte neo-realista tem de viver e vive no plano da liberdade. Inútil acusá-la de sacrifício ao político e ao social. Os seus criadores, como os de outras correntes, estão naturalmente enformando a realidade literária duma visão especial do mundo, mas quando é que isso não sucedeu assim? Acontece simplesmente que o ponto de vista dum Goethe ou dum Proust parece único e o do neo-realismo tem o aspecto duma manifestação coletiva dirigida. Mas isto é aparência. A distância, destacando melhor, tornou singular o que no tempo histórico tinha a marca da classe. 
[...] Reflectir o espírito do tempo com a mais ampla consciência da sua diversidade e da sua unidade é função do artístico. Em arte "o eterno" é o "circunstancial que dura" e nada mais. Por isso não há que censurar o neo-realismo, precisamente naquilo em que ele é a expressão inegável do tempo. ${ }^{18}$

Num pequeno espaço, Eduardo Lourenço trata de muitas coisas. A primeira é a que nos interessa mais diretamente aqui. O engajamento é usualmente visto como algo que cerceia a liberdade de criação. o crítico rompe com a idealização que a ideia de uma liberdade artística sem limites representa e nos pergunta quando o artista foi assim absolutamente livre. Ora, sempre se cria dentro dos limites de uma visão do mundo e, por isso, vale indagar por que razão, de saída, uma visão de mundo produziria arte mais livre do que outra.

Introduz a seguir uma visada histórica ampla e nos fala do que haveria de comum entre os "grandes" autores e os escritores "comuns" de uma época, semelhança que o tempo tende a apagar. Mais uma vez rompe com uma concepção idealizada, agora a do gênio capaz de produzir obras eternas, reduzindo o eterno à dimensão temporal que toda ação humana tem. Chegará, a seguir, no plano concreto das realizações individuais:

Verdadeiramente muitas críticas colhem certos neo-realistas, não o neo-realismo. Este é apenas uma unidade ideal, como tal abstracta, que exige evidentemente no plano da concretização, as mais reais e profundas diferenças. Em arte, a ideia existe unicamente encarnada no diverso e no múltiplo. A verdade dum romance ou duma poesia (se se pode falar assim) não é a verdade lógica dum ensaio. Não existe dum lado o esquema ideal, verdadeiro, e do outro algo a que seja preciso dar um certo sentido para se ajustar àquele quadro. [...]

Uma certa monotonia que cobre algumas realizações neo-realistas não pode significar falência interna, mas apenas incapacidade de seus cultores. O limbo da arte neo-realista está cheio de belas intenções que como Moisés jamais pisarão a Terra Prometida. ${ }^{19}$

Neste trecho aparece, sem dúvida, o estudante de filosofia que naquele mesmo ano de 1946 se graduaria com um trabalho chamado $O$ sentido da dialéctica no idealismo absoluto, capaz de distinguir entre as realizações concretas e o escopo geral de uma doutrina. Assim, o neorrealismo ter gerado 
obras falhadas não implica necessariamente uma falência de princípio. 0 movimento, é sempre bom lembrar, estava dando seus primeiros frutos. É preciso analisar a natureza das falhas no que elas têm de específico. Daí a importância de ver exatamente quais seriam os limites e qualidades de Casa da duna, antes de proclamar a inutilidade de uma proposta ampla de que Casa da duna é uma manifestação apenas.

Passados mais de 20 anos desses primeiros escritos, Eduardo Lourenço dedicaria um estudo mais alentado sobre a poesia neorrealista ou, para ser mais preciso, sobre três poetas neorrealistas: João José Cochofel, Joaquim Namorado e Carlos de Oliveira. Esse intervalo de tempo fez com que um grupo em processo de se firmar se convertesse noutra coisa muito diversa, a encarnação do pensamento hegemônico de um tempo. Na introdução ao capítulo sobre Cochofel, não é sem melancolia que o crítico vai constatar essa transformação naquela que é a sua própria geração:

Mesmo se os "poetas de hoje" são, sobretudo, de ontem, não é motivo para os ignorar. A colecção com esse título, contudo, não deixará de despertar uma certa melancolia a leitores, como nós, para quem os poemas de "hoje" foram a poesia de nossa geração agora nobre e confortavelmente deitada em volumes da boa companhia, na aparência, definitivos. À poesia que estava dentro de frágeis edições originais de há trinta anos, o que sucedeu? ${ }^{20}$

O mais importante para o que estamos seguindo aqui, no entanto, está em localizar, na obra da maturidade, o que ficou do pensamento do intelectual aspirante. E não é absurdo adiantar a resposta e dizer que tudo ficou. As linhas de força que se definiram nos textos publicados pela revista Vértice reaparecem claramente no decisivo "Prólogo" com que Eduardo Lourenço faz anteceder seus estudos sobre os três poetas. Ali ele começa por afirmar, como já vimos, a peculiaridade da longa fase teórica que antecipou a produção de literatura criativa para chegar ao problema da liberdade de criação no interior de uma concepção de arte engajada:

Sem dúvida, os autores neo-realistas conservaram sempre a fidelidade ideológica como horizonte da sua criação e assim, de algum modo, voluntariamente se anteciparam a si mesmos, o que traduzido noutro registo pode confundir-se com mutilação ou 
com voluntário sacrifício. Todavia, nos mais representativos, este horizonte, cuja presença é inegável mas cuja imobilidade é menos absoluta do que parece, não só não coarctou as possibilidades de expressão àqueles que o escolheram, como foi para eles o espaço de libertação e o sinal da autêntica liberdade. [...] Mesmo que se admita que a Ideologia comporta consequências que colidem com uma concepção mais bem fundada na liberdade espiritual, o simples facto de ela ter sido eleita por aqueles que ninguém obrigava a perfilhá-la os tornaria livres. Uma prisão que nós escolhemos por essa escolha se torna a nossa casa.

Acontece, porém, que nenhum autor neo-realista supôs jamais que a sua casa fosse uma prisão. Ao contrário, escolheu-a, adoptou-a, defendeu-a [...] como a única habitável. ${ }^{21}$

Não é difícil perceber como, em sua essência, as observações que precediam em 1946 a análise de Casa na duna se mantêm - e são ampliadas. A ideia de liberdade de criação se recoloca mais ou menos nos mesmos termos. Mais do que coerência, no entanto, o que encontraremos é um profundo desdobramento. Neste novo contexto o crítico vai muito além de uma defesa do neorrealismo enquanto estética possível para extrair o drama central - e portanto comum - vivido pela poesia neorrealista:

Assim, a sua autêntica experiência, o motor único das suas criações não pode ser mais que o do abismo entre o sonho plausível e o obstáculo, o que não os impediu de tentar acreditar esse sonho diante dos outros (e nos melhores, a intervalos, diante de si mesmos), em suma, de apelar com persistência para uma esperança e um futuro que o dia a dia também com persistência bloqueava. ${ }^{22}$

Num golpe dialético, é negando o caráter coercivo da ideologia comum que Eduardo Lourenço localizará o que há de profundamente semelhante, para além dos condicionamentos prévios, e que brotará exatamente do mergulho naquela ideologia. É da utopia de uma sociedade mais justa, nascida daquele ideário muitas vezes tido por limitante, e de seu choque com um real que resiste à utopia, que, segundo ele, a poesia neorrealista encontrará seu lugar específico na cultura portuguesa.

E, poderíamos acrescentar a partir do que diz Eduardo Lourenço, num tempo em que a literatura engajada anda em baixa, esse impasse reence- 
nado pelo neorrealismo português só não nos interessaria hoje caso a justiça tivesse sido plenamente instalada no mundo ou, ao contrário, se tivéssemos abandonando cinicamente de vez a esperança, desistido de instaurá-la.

\section{REFERÊNCIAS}

BUENO, Luís. O Brasil invade Portugal - Literaturas brasileira e portuguesa na década de 1930. In: PONCIONI, Claudia; ESTEVES, Manuel da Costa. Hommes de lettres et la Res publica au Portugal e au Brésil. Paris: Michel Houdiard, 2013. p. 225-236.

LOURENÇO, Eduardo. Aceitação. Vértice, Coimbra, n. 3, fev. 1941. p. 9. . Ilha doida de Joaquim Ferrer. Vértice, Coimbra, n. 4-7, fev. 1945. p. 60-62. . Casa da malta de Fernando Namora. Vértice, Coimbra, n. 22-26, fev. 1946. p. 27-29. . Alcateia por Carlos de Oliveira. Vértice, Coimbra, n. 12-16, mai. 1945. p. 52-54. . Sentido e forma da poesia neo-realista. 2 ed. Lisboa: Gradiva, 2007. p. 27. . "Meus heterónimos são máscaras transparentes". Ler. Livros \& Leitores. Lisboa, n. 84, out. 2009. p. 54-59. Entrevista a Carlos Câmara Leite.

RAIMOND, Viviane. A revista Vértice e o neo-realismo português. Coimbra: Angelus Novus, 2008.

Submetido em: $11 / 08 / 2014$

Aceito em: $17 / 10 / 2014$ 